\title{
Pediatric concussion: biomechanical differences between outcomes of transient and persistent ( $>4$ weeks) postconcussion symptoms
}

\author{
Andrew Post, PhD, ${ }^{1,2}$ T. Blaine Hoshizaki, PhD, ${ }^{2}$ Roger Zemek, MD, ${ }^{1}$ Michael D. Gilchrist, PhD, ${ }^{3}$ \\ David Koncan, MSc, ${ }^{2}$ Lauren Dawson, MSc, ${ }^{2}$ Wesley Chen, BSc, ${ }^{2}$ Andrée-Anne Ledoux, PhD, ${ }^{1}$ and \\ the Pediatric Emergency Research Canada (PERC) 5P Concussion Team
}

${ }^{1}$ Children's Hospital of Eastern Ontario Research Institute, Ottawa; ${ }^{2 H u m a n}$ Kinetics, University of Ottawa, Ontario, Canada; and ${ }^{3}$ School of Mechanical \& Materials Engineering, University College Dublin, Ireland

\begin{abstract}
OBJECTIVE Currently, little is known about the biomechanics of head impact for concussion in youths (ages 5 to 18 years). Even less is known about the biomechanical characteristics and variables related to head impacts that may be useful in differentiating between transient and persistent postconcussion symptoms in a youth population. The purpose of this research was to examine the differences in biomechanics of youth head impact for transient postconcussion symptoms (TPCSs) and persistent postconcussion symptoms (PPCSs) by using data from a hospital population.

METHODS In a laboratory setting and using physical, computational, and finite element models, the authors reconstructed falling events in a large cohort of patients who had sustained a brain injury that resulted in transient or persistent postconcussion symptoms. The falling events and resulting concussions for the TPCS and PPCS patient groups were analyzed in terms of force, energy, peak resultant linear and rotational accelerations, and maximum principal strain in the gray and white matter of the brain, as well as measurements of cumulative strain damage.

RESULTS The results indicated that there were no significant differences between the groups for any of the variables analyzed.

CONCLUSIONS With methods derived for use in an adult population, the magnitudes of peak linear acceleration for the youth data set were determined to be above the $50 \%$ risk of injury. The youth data set showed higher brain tissue strain responses for lower energy and impact velocities than measured in adults, suggesting that youths are at higher risk of concussive injury at lower event severities. A trend shown by some variables indicated that larger magnitudes of response were associated with PPCSs, but no single measurement variable consistently differentiated between the TPCS and PPCS groups. It is possible that using the biomechanics of head and brain responses to predict a subjective symptom load may not be appropriate. To enhance future biomechanical analyses, further investigations should include the use of quantifiable measures of brain injury linked to clinical outcomes and possible confounding factors such as history of brain injury and patient predisposition.
\end{abstract}

https://thejns.org/doi/abs/10.3171/2016.11.PEDS16383

KEY WORDS concussion; persistent postconcussion symptoms; biomechanics; youth; pediatric; trauma

$\mathrm{L}$ ITTLE is known about the biomechanics of concussion in youths, as the majority of biomechanical investigations have been performed in adults. .9,52,72 $^{29}$ Biomechanical research has established that concussion often occurs through head impact that results in movement of the head, which causes stress and strain to the brain tissues. ${ }^{18,32}$ Youths in particular have been shown to be at risk for this type of brain injury, with 750,000 concussionrelated visits to emergency departments (EDs) annually in the United States alone..$^{15,40}$ The greatest concussion risk to youths has been reported to be falls in sporting environments, with up to $47 \%$ of sport-related brain injuries occurring as a result of these events. ${ }^{59,69}$ Youths have also been found to suffer more adverse consequences from the

ABBREVIATIONS CFC = channel frequency class; $\mathrm{CSDM}$ = element cumulative strain damage measure; $\mathrm{DTI}=$ diffusion tensor imaging; $\mathrm{ED}=$ emergency department; MADYMO = mathematical dynamic models; MPS = maximum principal strain; PERC = Pediatric Emergency Research Canada; PPCS = persistent postconcussion symptom; SWI = susceptibility-weighted imaging; TBI = traumatic brain injury; TPCS = transient postconcussion symptom; UCDBTM = University College Dublin Brain Trauma Model. SUBMITTED July 4, 2016. ACCEPTED November 30, 2016.

INCLUDE WHEN CITING Published online March 28, 2017; DOI: 10.3171/2016.11.PEDS16383. 
effects of concussion than their adult counterparts, particularly when long-term symptoms are present, as these can affect scholastic performance and lead to absenteeism from school, loss of social activities, and lower quality of life. ${ }^{2}$ Concussion symptomology can be separated into 2 types: transient postconcussion symptoms (TPCSs; in which symptoms resolve within the initial few weeks after injury), or persistent postconcussion symptoms (PPCSs; in which 3 or more symptoms, including physical symptoms, cognitive problems, mood changes, sleep disturbances, and behavior changes, are present for longer than 4 weeks). ${ }^{2,67,70}$ Currently, it is unknown if there are biomechanical parameters of head impact that may differentiate between these 2 outcomes in a youth population.

Rotational acceleration and strain in the brain tissues are important parameters when it comes to defining risk of concussion, with maximum strain levels associated with a $50 \%$ probability of concussion proposed in the literature. ${ }^{29,47,54,72}$ PPCSs have been examined in adults, with the hypothesis that long-term symptoms are associated with higher-magnitude impacts than have been reported for TPCS..$^{25,52}$ Higher-magnitude impact events may cause more damage to brain tissue, resulting in a greater symptom burden and longer recovery duration. ${ }^{18}$ Although this relationship has been postulated for adults, little is known about the biomechanics of concussion in youth populations and whether the mechanisms of injury that are associated with PPCSs differ from those of TPCSs.

Most investigations examining the biomechanical implications of trauma to the pediatric brain have been performed in animal models. Based on data scaled from concussion studies in animals, Ommaya et al. ${ }^{44}$ suggested that the rotational acceleration threshold for an infant brain mass $(400 \mathrm{~g})$ was around 10 to $15 \mathrm{krad} / \mathrm{sec}^{2}$. Although they did not specifically examine concussion, Roth et al..$^{53}$ developed a finite element model for 3-year-old children and investigated traumatic brain injury (TBI) by reconstructing TBI events in infants. These investigators found that finite element model outputs in stress and strain were more predictive of brain injury than parameters based on linear and rotational acceleration. In an analysis performed in neonatal pigs, Eucker et al..$^{12}$ found a significant effect of plane of rotation on brain injury outcome. They concluded on the basis of their research that the tissue strains that result in concussion are directly affected by the mechanical loading created by head rotation. In an examination of impacts to 5-day-old and 4-week-old piglets (which correspond to infants and toddlers in comparative brain tissue composition), Weeks et al. ${ }^{63}$ demonstrated that the younger age group was more susceptible to longer-lasting metabolic effects of traumatic axonal injury, indicating that the age of the brain can influence the duration of pathophysiological responses for similar impacts.

What is currently known about the biomechanics of pediatric concussion is from adult data obtained in adult brain injury environments, ${ }^{8,17,52,72}$ not youth environments. Therefore, little information is known about youth concussion, particularly in the 5- to 18-year-old age group. In addition, to our knowledge no research has been conducted to examine the differences in what characterizes TPCS versus PPCS outcome in youths. The purpose of the present study was to examine the biomechanical differences between TPCSs and PPCSs in youths from an ED population.

\section{Methods}

Participants

All patients for this research were recruited from 9 pediatric EDs inside the Pediatric Emergency Research Canada (PERC) network. Approval for this study was granted by the Research Ethics Board. The patients ranged in age from 5 to 18 years; to be enrolled in the study, patients met the concussion diagnostic assessment criteria as described in the Zurich consensus statement. ${ }^{31}$ The inclusion and exclusion criteria used in this study were detailed thoroughly by Zemek et al. ${ }^{70}$ with 3063 young patients (ages 5 to 18 years) enrolled. The Zemek et al. ${ }^{70}$ research was a multicenter cohort study in which patients and their parents/ legal guardians provided information using tools such as the Acute Concussion Evaluation symptom checklist, ${ }^{16}$ the Postconcussion Evaluation inventory, ${ }^{57}$ and the third edition of the Child-Sport Concussion Assessment Tool (Child SCAT3). ${ }^{7}$ Patients and/or their parents/guardians completed follow-up surveys at 1,2 , and 4 weeks postinjury. A wide variety of symptoms were categorized into the following clinical domains: somatic, cognitive, emotional/behavioral, and sleep. ${ }^{70}$ To be included in the PPCS group, the patients must have had 3 or more symptoms for a duration longer than 4 weeks. ${ }^{70}$ Patients not meeting these criteria, with symptoms abating before 4 weeks, were identified and included in the TPCS group. To conduct the biomechanical reconstruction of the TPCS and PPCS impact events, the assessment of each patient included a questionnaire that detailed the characteristics of the impact. This questionnaire was completed by the patient and/or the parent/guardian of the patient to ensure as much accuracy in the description of the event as possible. These characteristics included the type of impact, location of impact on the head, impact surface, and a description of the event to aid in the laboratory reconstruction. Of this data set, only falls were reconstructed, because for an accurate reconstruction of collision-type events there was not enough information available regarding the body positions and velocities of those involved. To be included in this research as a "fall," the event must have been a vertical gravity-related event (e.g., fall directly onto the ice or grass) and not a fall into boards or goalposts where the subject might have been traveling at a high rate of horizontal velocity. Of the total of 3063 patients included in the study, 235 had enough detailed information to allow for a biomechanical reconstruction in the laboratory (Fig. 1).

\section{Procedure}

To conduct the reconstructions of the falls, a combination of mathematical modeling, physical reconstruction, and finite element modeling was used. The parameters of impact location on the head and impact surface were determined from the patient and parent/guardian interviews. As velocity of impact cannot be determined from interviews, the height of the individual and description of the impact environment were used to conduct simulations using MADYMO (mathematical dynamic models; Tass 


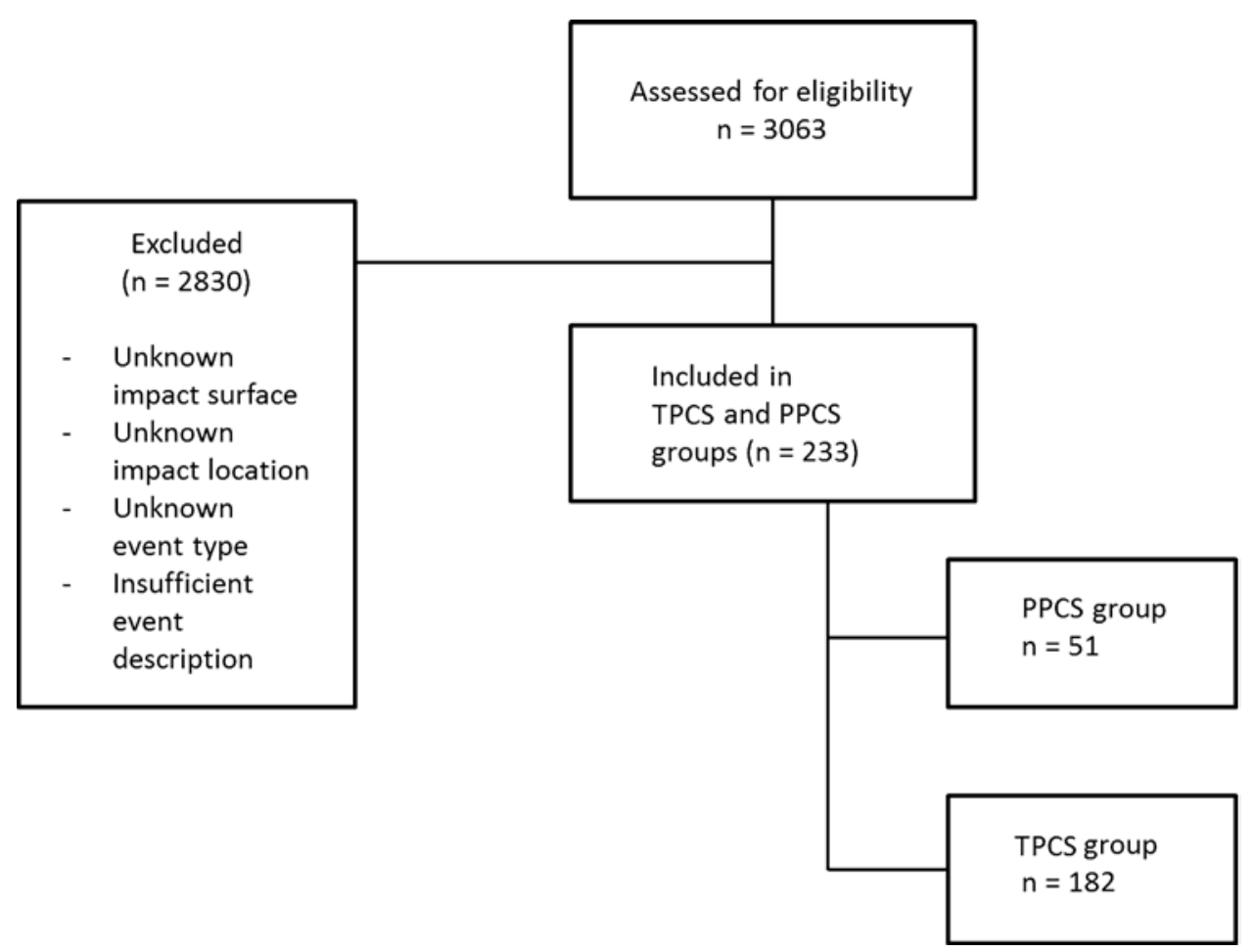

FIG. 1. Inclusion and exclusion flowchart for the biomechanical reconstructions.

International) to determine the head contact velocity for the event. Once the parameters of impact location, surface, and velocity were determined, impacts were created using a monorail system and a Hybrid III headform (Humanetics ATD). A Hybrid III headform closely approximating the head size of the target population, as described in the literature (Table 1) was affixed to the monorail via an unbiased neckform (a symmetrical neckform with no mechanical bias) in a position that allowed for the correct impact site to be contacted once released, simulating the fall (Walsh ES, Hoshizaki TB: "Comparative analysis of the Hybrid III neckform to unbiased neckforms using a centric and non-centric impact protocol," presented at the ASTM Symposium on the Mechanism of Concussion in Sports, Atlanta, November 13, 2012). The monorail lifted the headform to the height required to achieve the velocity of impact as determined from the MADYMO simulations, and the anvil was changed to reflect the surface of impact as described in the interviews. The outputs of the impacts were measured in linear and rotational acceleration time histories, which were used as inputs for finite element modeling of the human brain to determine the strain to the brain tissues. As the MADYMO output provided a range of possible impact velocities (upper and lower limits), 3 impacts were conducted per reconstruction velocity.

\section{Equipment}

Monorail

To simulate the falls, a monorail drop rig was used. The monorail was approximately $4.7 \mathrm{~m}$ long and had a carriage attached to it with a pneumatically controlled release lever. The headform was attached to the carriage via a neckform that allowed for the positioning of the head in
5 degrees of freedom to impact the appropriate location, as described by the patient. The impact velocity was determined by a photoelectric time gate positioned within 0.02 $\mathrm{m}$ of the impact. The anvil was affixed at the bottom of the monorail. The composition of the anvil varied depending on the environment in which the injury occurred. The anvils used were concrete, ice, turf, hardwood, and steel. The ice anvils were created by freezing water at $-25^{\circ} \mathrm{C}$ for 24 hours in a circular container (depth $0.096 \mathrm{~m}$, circumference $0.204 \mathrm{~m}$ ). The anvil was refrozen for 5 minutes between impacts to ensure that it did not melt during testing. The turf anvil was composed of a $0.26 \times 0.31 \times 0.05-\mathrm{m}$ sheet of field turf (standard depth $0.032-0.05 \mathrm{~cm}$; www. fieldturf.com). The hardwood was hardwood flooring attached to a standard subfloor with $2 \times 6-$ in, $90-\mathrm{cm}$ board supports to ensure rigidity.

\section{Headforms and Helmets}

Three different headforms were used for the injury reconstructions. The Hybrid III 50th, 5th (female), and 6-year-old (scaled relative to adult sizes), which represented the range of head sizes and masses of the patients whose fall data were included in the laboratory recon-

TABLE 1. The Hybrid III headform used for each age range as described in the literature

\begin{tabular}{lccc}
\hline Headform & $\begin{array}{c}\text { Circumference Range } \\
(\mathrm{cm})\end{array}$ & $\begin{array}{c}\text { Male Age } \\
(\mathrm{yrs})\end{array}$ & $\begin{array}{c}\text { Female Age } \\
(\mathrm{yrs})\end{array}$ \\
\hline 6-yr-old & $0-52.9$ & $6-7$ & $6-9$ \\
\hline 5th & $52.9-56.4$ & $8-16$ & $10-18$ \\
\hline 50th & $56.4-59.0$ & $17-18$ & \\
\hline
\end{tabular}


structions, were used as specified in the literature (Table 1). ${ }^{26,41,43,74}$ The headforms were outfitted with 9 Endevco 7264C-2KTZ-2-300 accelerometers (Meggitt Sensing Symptoms) in a 3-2-2-2 array for the measurement of linear and rotational accelerations. ${ }^{46}$ The accelerometers were sampled at $20 \mathrm{kHz}$. The signals were recorded by a computer and TDAS software (Diversified Technical Systems, Inc.), with the 50th headform filtered with a CFC (Channel Frequency Class) 1000 filter and the 5th and 6-year-old headforms with a CFC 180 filter. The frame of reference for the headform was $\mathrm{x}$-axis forward, $\mathrm{y}$-axis to the left of the head, and z-axis upward.

The reconstruction data set included everyday falls as well as sports falls (Fig. 2). The sporting falls were from 4 sports: ice hockey (falls exclusively to the ice), Canadian football, soccer, and basketball. Helmets and masks were worn by youths participating in ice hockey and Canadian football. An appropriately sized vinyl nitrile ice hockey helmet and mask was fitted to the headform for the ice hockey reconstructions. The same method was followed for the Canadian football reconstructions with an appropriately sized youth vinyl nitrile and liner (SKYDEX) Canadian football helmet fitted to the headform. A new helmet was used when the impact site coincided with a previously impacted location. Locations were identified as the same when they were within $5 \mathrm{~cm}$ of each other. The helmet response and physical condition were monitored, and any degradation in composition (cracks in the shell or liner) or protective capacity led to the replacement of the helmet with a new model.

\section{MADYMO Simulation}

MADYMO is a computational software tool commonly used in the automotive industry to simulate falling and pedestrian accidents based on eyewitness and accident victim reports. ${ }^{1}$ MADYMO incorporates subject kinematics during a fall to provide head contact velocity predictions that are more accurate than those determined using simple energy-based falling equations..$^{10,13,45,51}$ The power of this software lies in its database of human ellipsoid models that were validated for pedestrian impacts. In our research on pediatric concussions, an ellipsoid model that closely matched the anthropometrics of the pediatric patient case was chosen and placed in a virtual environment that was similar to that in which the study participant was

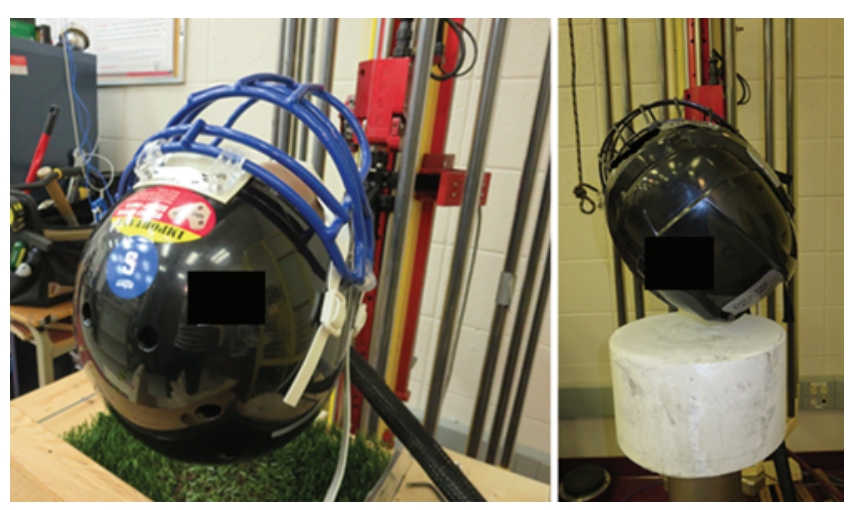

FIG. 2. Reconstruction impacts on the monorail for Canadian football (left) and ice hockey (right). Figure is available in color online only. injured. The ellipsoid model was then allowed to simulate the fall and head impact, and the final head contact velocity was measured. As there can be variation in accuracy of eyewitness and subject reports, a sensitivity analysis was conducted. ${ }^{10,13,51}$ Several simulations were performed for each case, each with different plausible joint angles and body positions that allowed for the head to be contacted in the identified location. From this analysis, the fastest and slowest head contact velocities were established for each case and were used as the impact velocities for the reconstructions.

\section{Finite Element Model}

To determine the maximum principal strain in the brain tissues, the University College Brain Trauma Model (UCDBTM) was used. ${ }^{23,24}$ The model geometry was determined from medical imaging of the head of a male cadaver, with the following sections included: scalp, skull, pia mater, falx, tentorium, CSF, gray and white matter, cerebellum, and brainstem. ${ }^{24}$ In total, the UCDBTM has approximately 26,000 hexahedral elements.

The material properties of the model were obtained from cadaveric anatomical and tissue sample research ${ }^{30,55,64,71,73}$ (Tables 2 and 3). The tissues of the brain were modeled using a linearly viscoelastic model combined with large deformation theory. The behavior of the brain tissues was characterized as viscoelastic in shear with a deviatoric stress rate dependent on the shear relaxation modulus. ${ }^{23}$ The compression of the brain tissue was defined as elastic. The shear characteristic of the viscoelastic brain was expressed as

$\mathrm{G}(\mathrm{t})=\mathrm{G}_{\infty}+\left(\mathrm{G}_{0}-\mathrm{G}_{\infty}\right) \mathrm{e}^{-\beta \mathrm{t}}$,

with $\mathrm{G}_{\infty}$ representing the long-term shear modulus, $\mathrm{G}_{0}$ the short-term modulus, and $\beta$ the decay factor. A MooneyRivlin hyperelastic material model was used for the brain to maintain these properties in conjunction with a viscoelastic material property in ABAQUS, giving the material a decay factor of $\beta=145 \mathrm{sec}^{-1}$. 22 The hyperelastic law was given as

$$
\mathrm{C}_{10}(\mathrm{t})=0.9 \mathrm{C}_{01}(\mathrm{t})=620.5+1930 \mathrm{e}^{-\mathrm{t} / 0.008}+1103 \mathrm{e}^{-\mathrm{t} / 0.15}(\mathrm{~Pa}),
$$

where $\mathrm{C}_{10}$ is the mechanical energy absorbed by the material when the first strain invariant changes by a unit step input, $\mathrm{C}_{01}$ is the energy absorbed when the second strain invariant changes by a unit step, ${ }^{33,35}$ and $t$ is the time in seconds. The skull-brain interaction was defined as sliding with no separation between the CSF and the pia mater. The CSF was modeled using solid elements with a bulk modulus of water and a low shear modulus. ${ }^{23,24}$ The coefficient of friction for the sliding interface was 0.2. ${ }^{36}$

Validation of the model was accomplished by comparing the UCDBTM's responses to the cadaveric pressure time histories from impacts conducted by Nahum et al..$^{39}$ Brain motion validations were established through comparisons to the cadaveric impacts reported by Hardy et al. ${ }^{21}$ Further comparisons of model responses were conducted using brain injury reconstructions from real-life incidents reported by Doorly, ${ }^{10}$ Doorly and Gilchrist, ${ }^{11}$ Rousseau,${ }^{54}$ and Post et al., ${ }^{52}$ and the results of these comparisons dem- 
TABLE 2. Material properties for UCDBTM

\begin{tabular}{llcc}
\hline Material & $\begin{array}{c}\text { Young's Modulus } \\
(\mathrm{MPa})\end{array}$ & $\begin{array}{c}\text { Poisson's } \\
\text { Ratio }\end{array}$ & $\begin{array}{c}\text { Density } \\
\left(\mathrm{kg} / \mathrm{m}^{3}\right)\end{array}$ \\
\hline Dura mater & 31.5 & 0.45 & 1130 \\
\hline Pia mater & 11.5 & 0.45 & 1130 \\
\hline Falx & 31.5 & 0.45 & 1140 \\
\hline Tentorium & 31.5 & 0.45 & 1140 \\
\hline CSF & Water & 0.5 & 1000 \\
\hline Gray matter & Hyperelastic & 0.49 & 1060 \\
\hline White matter & Hyperelastic & 0.49 & 1060 \\
\hline
\end{tabular}

onstrated good agreement with the magnitudes of strain and stress reported in the literature.

\section{Brain Size Scaling}

Finite element modeling involving children and adolescents was conducted using 2 scaled versions of the UCDBTM. Currently, there is little agreement concerning the parameters that should be used for the tissue definitions of a youth head model, with many researchers suggesting that these parameters in youths may be within the range of those reported for adults. ${ }^{5,53,56}$ This is an active area of research, and to date there is no accepted tissue definition for these age categories. As a result, the UCDBTM was scaled to represent the size and geometry of the age groups that were reconstructed in this research. For cases involving 6- to 7-year-old boys and 6- to 9-year-old girls, the impacts were modeled using a scaled version $(90 \%$ of the size of the regular UCDBTM). This size was chosen based on brain size data from MRI from Uchiyama et al., ${ }^{62}$ an average for the 6-year-old children involved in the study. Fit was emphasized in the anteroposterior and inferosuperior axes (within 1 standard deviation). For cases involving 8- to 16-year-old boys and 10- to 17-year-old girls, the impacts were modeled using another scaled version (95\% of the size of the standard UCDBTM). The size was chosen based on brain size MRI data from the study by Mennes et al. ${ }^{34}$ using a 50th percentile brain size for an age range of 2-15.99 years, emphasizing fit in the anteroposterior and inferosuperior axes.

\section{Measurement Variables and Statistical Analyses}

Comparisons of the TPCS and PPCS cases were conducted using force, energy, linear acceleration, rotational acceleration, and maximum principal strain in the gray and white matter. Force and energy are variables that are related to the severity of impact without taking into account the motion of the head as a result, and while not commonly used, these variables do provide an estimation of the severity of impact. Peak resultant linear acceleration is commonly used to estimate the risk of TBI, ${ }^{20,61}$ while peak resultant rotational acceleration has been linked to the mechanisms of concussion. ${ }^{22,50}$ Maximum principal strain in the gray and white matter is a metric that has been identified in the literature as being a variable that closely approximates the tissue level mechanisms of concussion. ${ }^{3,29,50,72}$ An element cumulative strain damage measure $\left(\mathrm{CSDM}^{\mathrm{e}}\right)$ was calculated from the finite element model output. This metric measures the percentage of ele-
TABLE 3. Material properties of brain tissue used in the UCDBTM

\begin{tabular}{lllcc}
\hline \multirow{2}{*}{ Material } & $\mathrm{G}_{0}$ & $\mathrm{G}_{\infty}$ & $\begin{array}{c}\text { Shear Modulus }(\mathrm{kPa}) \\
\text { Constant }\left(\mathrm{s}^{-1}\right)\end{array}$ & $\begin{array}{c}\text { Bulk Modulus } \\
(\mathrm{GPa})\end{array}$ \\
\cline { 2 - 3 } Gray matter & 10 & 2 & 80 & 2.19 \\
\hline White matter & 12.5 & 2.5 & 80 & 2.19 \\
\hline Brainstem & 22.5 & 4.5 & 80 & 2.19 \\
\hline Cerebellum & 10 & 2 & 80 & 2.19 \\
\hline
\end{tabular}

ments that passed a certain threshold of strain. This metric is similar to the CSDM in that it quantifies how much of the brain may have been damaged from an impact. ${ }^{4}$ As PPCSs might be associated with how much brain tissue was involved in the impact, with more tissue damage presenting as multiple symptoms, the $\mathrm{CSDM}^{\mathrm{e}}$ is a measure that might be used to differentiate between the TPCS and PPCS groups. For this analysis, the $\mathrm{CSDM}^{\mathrm{e}}$ was set to 0.1 and 0.2 maximum principal strain (MPS) levels. The 0.1MPS level was chosen because of its common usage in concussion analysis. ${ }^{17,47}$ The 0.2 -MPS level was chosen because this level of strain has been suggested as the amount of strain for which structural changes might occur in the brain tissues. ${ }^{3,38}$

Statistical analyses were conducted using t-tests to determine if there was a difference between the TPCS and PPCS groups for force, energy, peak resultant linear and rotational acceleration, and MPS, as well as for $\mathrm{CSDM}^{\mathrm{e}}$ set to $10 \%$ and $20 \%$. Significance was determined using a $\mathrm{p}$ value threshold of 0.05 . Further analyses using binary logistic regression were also conducted to determine if there was a predictive variable for these groups, also with a $\mathrm{p}$ value threshold of 0.05 . On completion of the statistical analyses, the youth impact responses were compared with those in the literature, and these results are presented in the Discussion.

\section{Results}

In total, 233 brain injury reconstructions were conducted from the original 3063 patients in the pan-Canadian cohort; 182 patients were in the TPCS group, and 51 were in the PPCS group. The distribution of TPCSs and PPCSs in the different risk environments were as follows: nonsport falls $\left(\mathrm{n}_{\mathrm{tpcs}}=66[36 \%], \mathrm{n}_{\mathrm{ppcs}}=15[29 \%]\right)$; ice hockey falls $\left(\mathrm{n}_{\mathrm{tpcs}}=66[36 \%], \mathrm{n}_{\mathrm{ppcs}}=19[37 \%]\right) ;$ Canadian football falls $\left(\mathrm{n}_{\text {tpcs }}=14[7.7 \%], \mathrm{n}_{\mathrm{ppcs}}=5[9.8 \%]\right)$; soccer falls $\left(\mathrm{n}_{\text {tpcs }}=\right.$ $\left.16[8.8 \%], \mathrm{n}_{\mathrm{ppcs}}=6[12 \%]\right)$; and basketball falls $\left(\mathrm{n}_{\mathrm{tpcs}}=20\right.$ $\left.[11 \%], \mathrm{n}_{\mathrm{ppcs}}=6[12 \%]\right)$. The age and sex distributions of the reconstruction data set can be found in Table 4 .

\section{Comparison of Biomechanical Variable Results for the TPCS and PPCS Groups}

The results for force, energy, peak resultant linear acceleration, peak resultant rotational acceleration, and MPS in the gray and white matter, as well as the $\mathrm{CSDM}^{\mathrm{e}}$, can be found in Figs. 3-6. The mean ( \pm SD) velocities of impact were $3.72 \pm 0.72 \mathrm{~m} / \mathrm{sec}$ for the TPCS group and $3.70 \pm$ $0.71 \mathrm{~m} / \mathrm{sec}$ for the PPCS group. There was no statistically significant difference on statistical comparison of the 2 groups for any variable $(\mathrm{p}>0.05)$. 
TABLE 4. Age and sex distribution for the reconstruction data set

\begin{tabular}{lccc}
\hline Risk Environment & Injury Type & Age in Yrs* & Sex Distribution \\
\hline \multirow{2}{*}{ Nonsport fall } & TPCS & $9.56(2.78)$ & $43 \mathrm{M}, 23 \mathrm{~F}$ \\
\cline { 2 - 4 } & PPCS & $9.97(4.34)$ & $4 \mathrm{M}, 11 \mathrm{~F}$ \\
\hline \multirow{2}{*}{ Basketball } & TPCS & $13.05(2.30)$ & $13 \mathrm{M}, 7 \mathrm{~F}$ \\
\cline { 2 - 4 } & PPCS & $14.63(0.95)$ & $3 \mathrm{M}, 3 \mathrm{~F}$ \\
\hline Soccer & TPCS & $12.91(2.37)$ & $7 \mathrm{M}, 9 \mathrm{~F}$ \\
\cline { 2 - 4 } & PPCS & $12.72(1.98)$ & $5 \mathrm{M}, 1 \mathrm{~F}$ \\
\hline Canadian football & TPCS & $13.84(1.55)$ & $14 \mathrm{M}, 0 \mathrm{~F}$ \\
\cline { 2 - 4 } & PPCS & $13.99(2.24)$ & $4 \mathrm{M}, 1 \mathrm{~F}$ \\
\hline Ice hockey & TPCS & $11.97(2.66)$ & $52 \mathrm{M}, 14 \mathrm{~F}$ \\
\cline { 2 - 4 } & PPCS & $13.30(2.36)$ & $15 \mathrm{M}, 4 \mathrm{~F}$ \\
\hline
\end{tabular}

${ }^{*}$ Mean (SD).

\section{Determination of Predictive Variable for PPCSs}

To determine if there was a variable that could predict the occurrence of PPCSs in this data set, a binary logistic regression was conducted. On completion of this analysis, it was found that no biomechanical variable had a statistically significant result that could identify the PPCS group $(\mathrm{p}>0.05)$.

\section{Discussion}

\section{TPCS Versus PPCS Groups}

To our knowledge, this study is the first in which a biomechanical analysis of a large cohort of pediatric concussion cases was conducted. The results of this analysis provide a data set that can be used to investigate brain injury in this unique population and reference concussion data for future analysis and validation of physical and computational models. In addition, these data allowed us to examine commonly used brain injury metrics in a pediatric concussion population and consider how these metrics might aid in predicting postconcussion symptoms. Overall, when all the data were grouped together, there was no single measurement variable that consistently differentiated between the TPCS and PPCS groups. Persistent postconcussion symptoms may be more related to the amount of tissue of the brain that has undergone deformation, which may be one reason why there was no significant differentiation in peak variables between these groups. The $\mathrm{CSDM}^{\mathrm{e}}$ allowed for an examination of how much tissue in the model had undergone a deformation that might produce concussive symptoms. ${ }^{17,47}$ When examining the $10 \% \mathrm{CSDM}^{\mathrm{e}}$, the TPCS and PPCS groups had similar responses, all indicative of a concussion. The $20 \% \mathrm{CSDM}^{\mathrm{e}}$, which is representative of how much of the brain may have undergone structural damage as suggested by Bain and Meaney ${ }^{3}$ and Morrison et al., ${ }^{38}$ showed slightly larger differences between the TPCS and PPCS groups. This finding indicates that more of the brain was incurring high strains in the PPCS group, which might have resulted in longer-term multiple-symptom presentation. ${ }^{18}$ This difference was not statistically significant, and further investigation of this particular phenomenon might require the use of a more tightly controlled reconstructive data set to reduce some of the variability seen using this
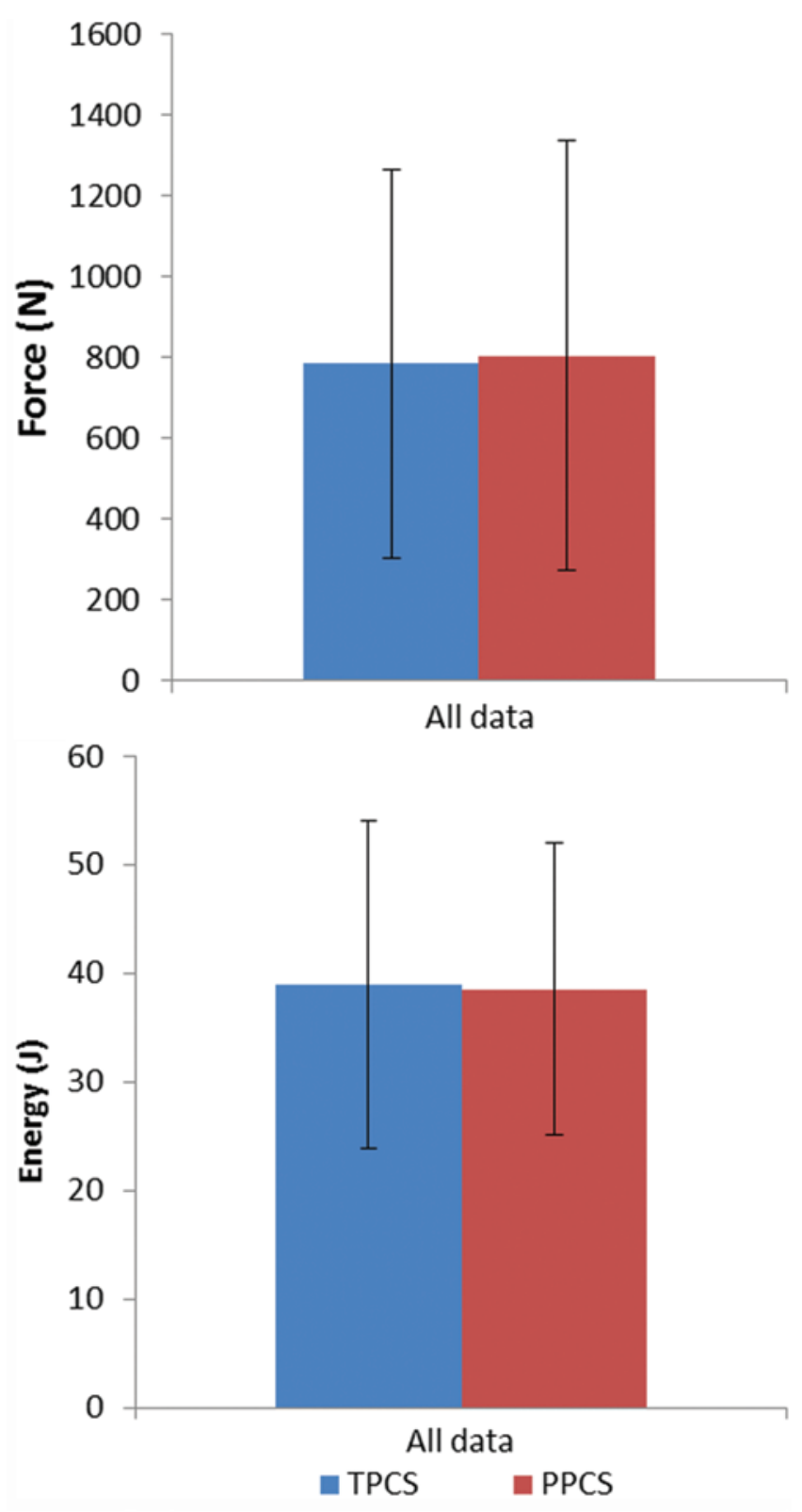

FIG. 3. Force (upper) and energy (lower) responses for the reconstructions comparing TPCS and PPCS groups for different injury environments. Bars indicate the mean, and error bars indicate the SD. Figure is available in color online only.

reconstruction method. These results differ somewhat from those for controlled animal experiments that have shown a correlation between the magnitude or direction of impact and the duration of measurable symptoms or the presence of pathophysiological responses observed after the animals had been euthanized..$^{18}$ Our experimental work did not benefit from controlled impacts where the input energy was kept equivalent between subjects, and even though this research was confined to environments of risk that limited the input variables somewhat (i.e., everyday falls and falls in ice hockey, basketball, football, and soccer environments), there was still large variation in falling input velocities between many of the subjects. 

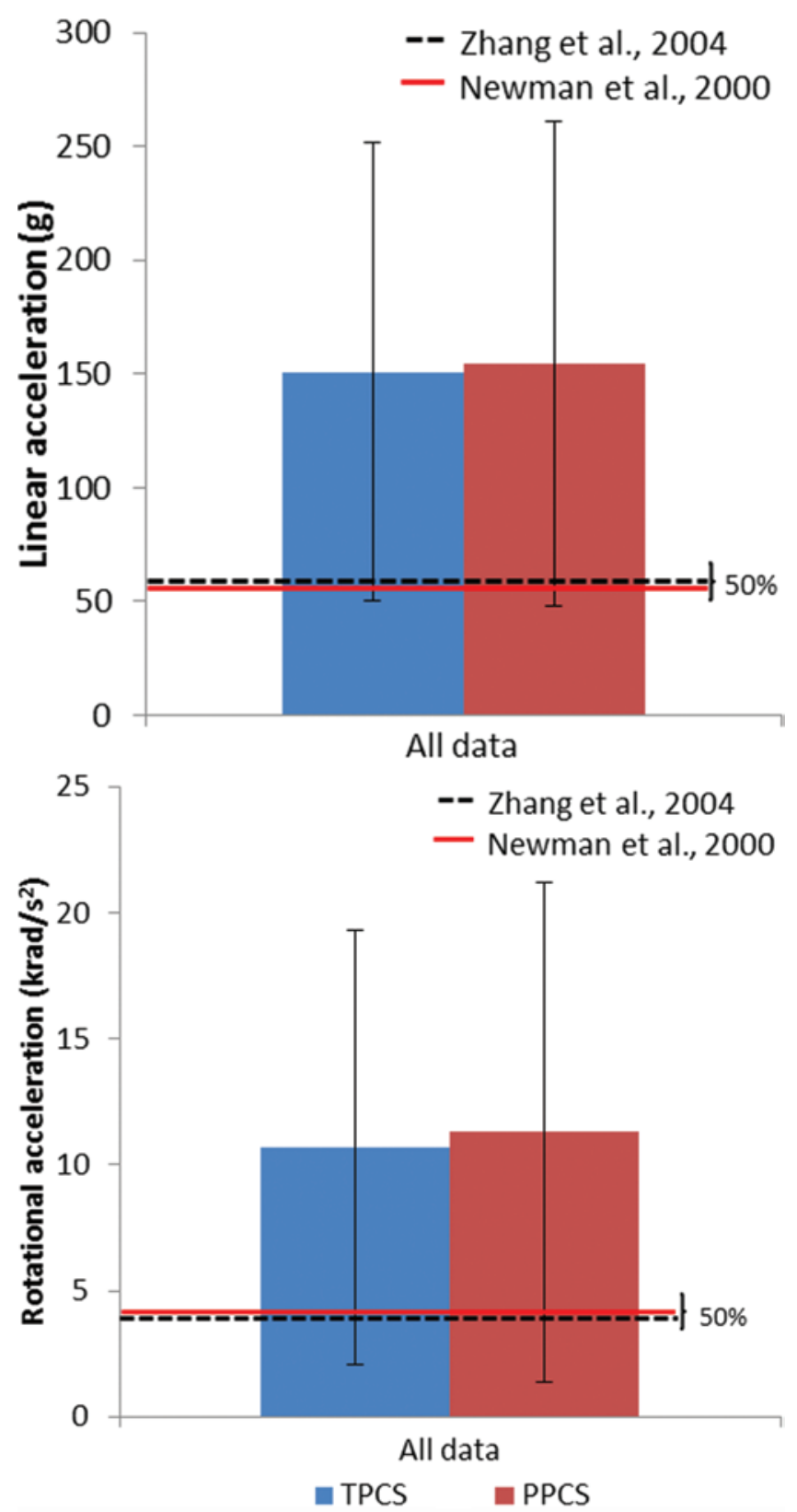

FIG. 4. Peak linear acceleration (upper) and peak resultant rotational acceleration (lower) comparing TPCS and PPCS groups for different injury environments with $50 \%$ risk of concussion according to the literature. Figure is available in color online only.

This variation in impact can be seen in our results (Figs. 4-6), as represented by large standard deviations for each measured dependent variable. In the future, it might be better to narrow the subject pool to just one type of impact, or environment of risk, to reduce variation as a result of different types of impacts, if sufficient patients can be found. In addition, the metrics used to quantify injury to the brain tissues were among the most commonly reported in the literature. Considering that injurious outcomes from impact are related to some form of mechanical damage and/or pathophysiological cascades, analysis of this data set with a more comprehensive set of dependent vari-
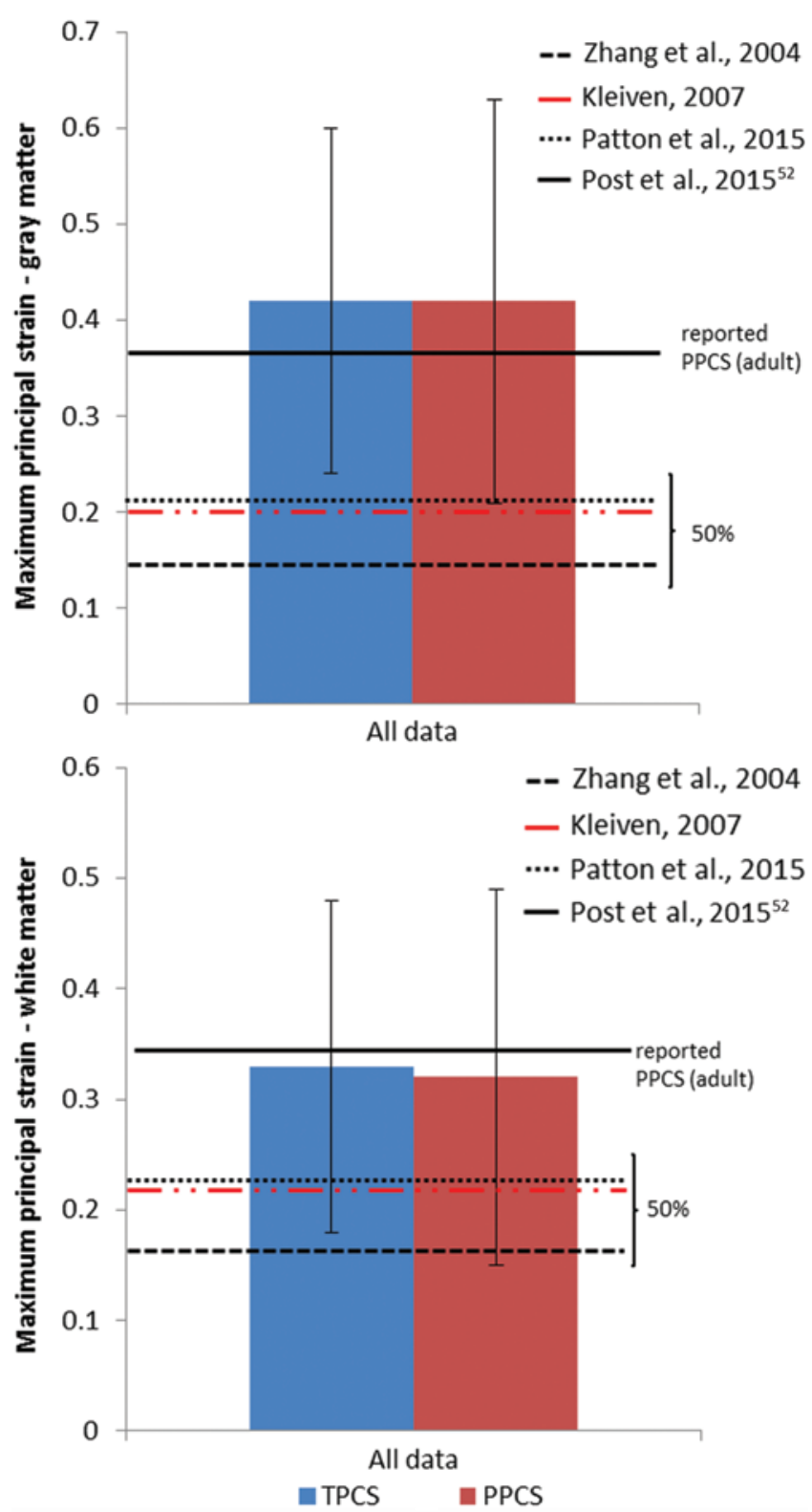

FIG. 5. Peak MPS in the gray matter (upper) and white matter (lower) comparing TPCS and PPCS groups for different injury environments with $50 \%$ risk of concussion from the literature. Figure is available in color online only.

ables, or improved finite element modeling techniques, may elucidate differences between the 2 groups analyzed in this research.

The lack of statistically significant differences with the use of these biomechanical measures may be a reflection of a lack of sensitivity in the protocol used to reconstruct the injuries, and also of the difficulties in matching a biomechanical tissue response to an injury identified using symptomology. It is possible that there was variation in the input parameters that might have occluded some statistically significant differences for the dependent variables chosen to quantify the impact in these cases. Each event was reconstructed on the basis of eyewitness reports, a method that is known to be a source of variation due to 

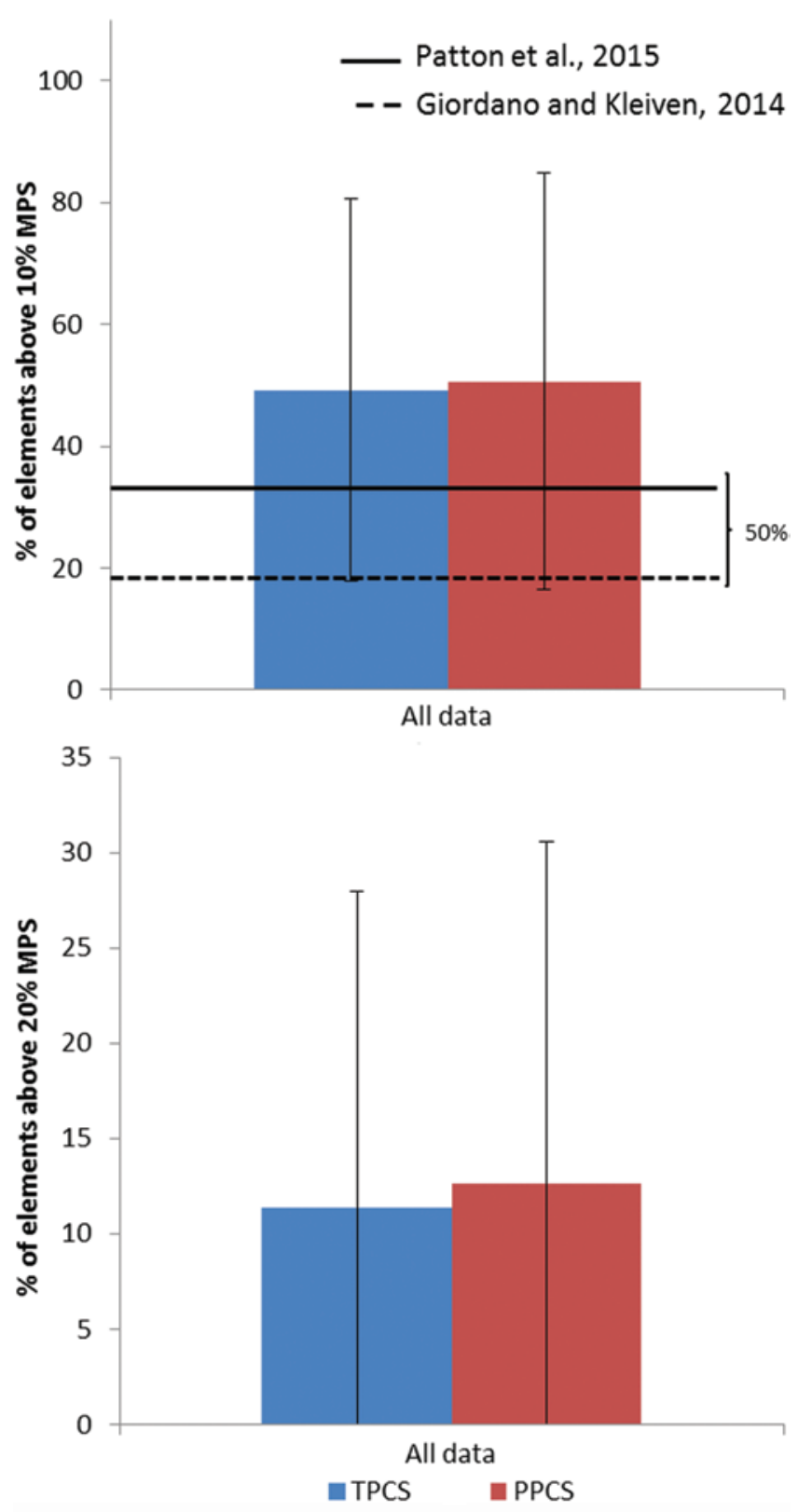

FIG. 6. Upper: CSDMe $10 \%$ responses in the cerebrum comparing TPCS and PPCS groups for different injury environments with $50 \%$ risk of concussion from the literature. Lower: CSDMe $20 \%$ responses in the cerebrum comparing TPCS and PPCS groups. There is no available comparison point in the literature for $20 \%$ strain CSDM. Figure is available in color online only.

errors in recalling these types of events. In our previous work we have used this technique for reconstruction in adults, ${ }^{52,54}$ and we found statistically significant results for TBI and persistent concussion syndrome; however, it may be the case that for youths this technique needs further refinement to narrow the variability of the impact parameters from report forms. The use of headforms that are rough approximations of the maturation status of youths is an area that may need refinement for future examinations of these populations, in addition to increased accuracy of reporting for the impact event, possibly through use of video analysis if available. These results may also indicate that, beyond certain variation in the biomechanical input, differences from patient to patient have more impact on the long-term symptomology than the initial impact, so long as that impact is of sufficient magnitude to cause some pathophysiological cascade for the individual. In effect, it may be more likely that outcome symptomology is not predictable using biomechanical parameters. It has also been reported that PPCSs may be related more to preexisting behavioral, learning, or family stressors after a concussion has occurred. ${ }^{37}$ Symptomology is a reflection of many factors that might not be directly related to injury to the tissues of the brain, ${ }^{14}$ such as fuzzy vision (retinal disturbance $^{58}$ or vestibular dysfunction resulting in dizziness. ${ }^{19}$ As a result, using a biomechanical parameter to quantify the injury may be problematic. There may be an improvement in predictability of the biomechanical measures with the development of quantifiable methods that are not dependent on symptomology to identify the presence and severity of concussion, such as diffusion tensor imaging (DTI) and other imaging modalities. Until such effort has been made, the biomechanical analyses may be able to identify trends that fit to some theories of injury mechanics but may be limited in terms of prediction of the outcome event.

\section{Comparison With the Concussion Literature}

This data set provided us with the opportunity not only to examine the relationships between TPCS and PPCS subgroups of concussion, but also to compare our results regarding youth concussion with data reported in the literature, which comprises risk-of-injury data sets from adult brain injury research. The methods used in our research were originally derived for use in an adult population; as a result, to our knowledge this study is the first use of such methods for a pediatric group. Overall, this method produced magnitudes of biomechanical variables that have been shown to be linked to brain injury consistent with concussive brain injury. Force and energy are not variables that are commonly used to examine concussion, and as a result there are no data available with which to conduct a comparison; however, there are data available that are based on the use of other parameters. Comparisons with the risk values reported in the literature can be found in Figs. 4-6. The magnitudes of peak linear acceleration determined for the youth data set were above the $50 \%$ risk of injury, as identified by the literature. ${ }^{42,48,72}$ Linear acceleration has been demonstrated not to be a causative factor in the mechanisms of concussion, $28,50,66$ but it can be used as a measure of the magnitude of impact. In that context, it would appear that these impacts had large responses, many in excess of $100 \mathrm{~g}$. Similar to the peak linear acceleration responses, the magnitudes of peak rotational acceleration were generally high, as would be expected from falls of these severities..$^{52,60}$ The magnitudes of linear and rotational acceleration incurred by youths in this research were also larger than those reported from impact sensor systems, with values in the range of $10-125 \mathrm{~g}$ and 52-7694 rad/s $\mathrm{s}^{2}, 8,65$ This difference likely reflects the fact that many of these impacts were collisions and not falls, which, due to the presence of padding, typically result in 
lower values for these metrics. In addition, the data in the literature were mostly from noninjurious cases, whereas in our study all of the patients were confirmed to have sustained concussions. Peak linear and rotational acceleration are good indicators of head kinematics from an impact, but these variables have been found to be lacking in terms of brain injury prediction because they do not account for the effect of an acceleration loading curve on the brain tissues themselves. ${ }^{49,68}$ The maximum values for principal strain responses in the gray and white matter of the cerebrum show that there was a high risk of concussion from these events, with at least a $50 \%$ risk. ${ }^{29,47,72}$ In comparison with the literature, the youth reconstructions in this study show that the strains to the brain tissues that resulted in TPCS and PPCS outcomes were generally larger than the TPCS and PPCS magnitudes reported for adults. ${ }^{29,47,52,72}$ The CSDM $10 \%$ responses show that both the TPCS and PPCS groups involve more brain tissue above 10\% MPS than what has been reported in the literature for concussion, ${ }^{17,47}$ which might indicate a susceptibility to having a larger amount of brain tissue involved in the impact of a fall. When placed in the context of the adult concussion data set collected from falling events ${ }^{52}$ in which the energies of impact are generally higher as a result of the patient being taller, the youth data set presented here had higher responses for lower energy and impact velocities, which supports the notion that youths are at higher risk of concussive injury at lower event severities. ${ }^{9}$

\section{Limitations}

The research we conducted used physical, computational, and finite element modeling methods for the reconstructions of brain injuries in youths. These methods were combined in a way that reduced the sources of error linked to using one method on its own, but still there are some inherent limitations. While the Hybrid III headforms used do represent the geometry and masses of the age groups studied and have been shown to produce magnitudes of response within the range of those for cadavers, ${ }^{27}$ they do not provide responses that reflect the variation found for head impacts in humans. In addition, the reconstruction parameters were determined from interviews of patients as well as witnesses and parents/guardians, and may be subject to a certain amount of recall error. To account for possible discrepancies, rigid inclusion criteria were applied, and simulations were conducted to account for many of the possible impact scenarios leading to injury. This method provided a reasonable amount of accuracy for the reconstruction, but it might not have resulted in an exact representation of the mechanics of impact. The use of the scaled UCDBTM is the current standard for youth impact research because of the lack of validation and anatomical data for the development of a youth-specific finite element model of the human brain for concussion research. While the material characteristics of the brain used were in the range of those for youths, it is likely that they are not fully representative of the population that was examined in this research study. Some of the patients in this research reported having sustained at least 1 previous concussion, but previous history of concussion was not considered in this investigation even though it may have been a factor in the results presented in this research. However, the average duration since the previous concussion was 864 days, and it is likely that the brain tissues had sufficiently recovered in that time. Even so, this relationship between previous concussion and vulnerability requires further investigation.

\section{Conclusions}

The results of the biomechanical comparison show that, although there was a trend shown by some variables indicating that the larger magnitudes of response were associated with PPCSs, there was no biomechanical measure that resulted in a statistically significant difference between the groups. This result may be a reflection of the general and imprecise method of using symptomology to define the TPCS and PPCS groups. As a result, future investigations should use a quantifiable measure to identify concussion groups, such as advanced neuroimaging techniques like structural MRI, DTI, and arterial spin labeling. In addition, the responses for concussion found for youth in this research are consistent with those found for adults. Considering that the youth responses in the research showed risk at lower impact severities, it would seem to indicate that youths might be more susceptible than adults to brain injury from lower-energy impacts.

\section{Acknowledgments}

This study was supported by Canadian Institutes of Health Research Operating Grant TM1 No. 127047 and Canadian Institutes of Health Research-Ontario Neurotrauma Foundation Mild Traumatic Brain Injury Team Grant No. 126197.

\section{Appendix Collaborators: PERC 5P Concussion Team}

Candice McGahern, BA; Gurinder Sangha, MD; Darcy Beer, MD; William Craig, MDCM; Ken J. Farion, MD; Angelo Mikrogianakis, MD; Karen Barlow, MD; Alexander S. Dubrovsky, MDCM, MSc; Willem Meeuwisse, MD, PhD; William P. Meehan III, MD; Yael Kamil, BSc; Anne M. Grool, MD, PhD, MSc; Blaine Hoshizaki, PhD; Peter Anderson, PhD; Brian L. Brooks, PhD; Michael Vassilyadi, MDCM, MSc; Terry Klassen, MD; Michelle Keightley, PhD; Lawrence Richer, MD; and Carol DeMatteo, MSc.

\section{References}

1. Adamec J, Jelen K, Kubovy P, Lopot F, Schuller E: Forensic biomechanical analysis of falls from height using numerical human body models. J Forensic Sci 55:1615-1623, 2010

2. Ayr LK, Yeates KO, Taylor HG, Browne M: Dimensions of postconcussive symptoms in children with mild traumatic brain injuries. J Int Neuropsychol Soc 15:19-30, 2009

3. Bain AC, Meaney DF: Tissue-level thresholds for axonal damage in an experimental model of central nervous system white matter injury. J Biomech Eng 122:615-622, 2000

4. Bandak FA, Eppinger RH: A three-dimensional finite element analysis of the human brain under combined rotational and translational accelerations. Stapp Car Crash J 38:279, 1994

5. Chatelin S, Constantinesco A, Willinger R: Fifty years of brain tissue mechanical testing: from in vitro to in vivo investigations. Biorheology 47:255-276, 2010

6. Chrisman SPD, Mac Donald CL, Friedman S, Andre J, Rowhani-Rahbar A, Drescher S, et al: Head impact exposure during a weekend youth soccer tournament. J Child Neurol 31:971-978, 2016 
7. Concussion in Sport Group: Child-SCAT3 Sport Concussion Assessment Tool for children ages 5 to 12 years. Br J Sports Med 47:263-266, 2013

8. Daniel RW, Rowson S, Duma SM: Head impact exposure in youth football. Ann Biomed Eng 40:976-981, 2012

9. Dawson L: Impact Characteristics Describing Concussive Injury in Youth [thesis]. Ottawa: University of Ottawa, 2016

10. Doorly MC: Investigations Into Head Injury Criteria Using Numerical Reconstruction of Real Life Accident Cases [thesis]. Dublin: University College Dublin, 2007

11. Doorly MC, Gilchrist MD: The use of accident reconstruction for the analysis of traumatic brain injury due to head impacts arising from falls. Comput Methods Biomech Biomed Engin 9:371-377, 2006

12. Eucker SA, Smith C, Ralston J, Friess SH, Margulies SS: Physiological and histopathological responses following closed rotational head injury depend on direction of head motion. Exp Neurol 227:79-88, 2011

13. Forero Rueda MA, Gilchrist MD: Comparative multibody dynamics analysis of falls from playground climbing frames. Forensic Sci Int 191:52-57, 2009

14. Gennarelli TA: Keynote lecture. The centripetal theory of concussion (CTC) revisited after 40 years and a proposed new symptomcentric concept of the concussions, in 2015 IRCOBI Conference Proceedings. Zurich: IRCOBI, 2015, pp IX-XIII (http://www.ircobi.org/wordpress/downloads/irc15/ pdf_files/02.pdf) [Accessed January 5, 2017]

15. Gilchrist J, Thomas K, Xu L: Nonfatal traumatic brain injuries related to sports and recreation activities among persons aged $\leq 19$ years-United States, 2001-2009. MMWR Morb Mortal Wkly Rep 60:1337-1342, 2011

16. Gioia GA, Collins M, Isquith PK: Improving identification and diagnosis of mild traumatic brain injury with evidence: psychometric support for the acute concussion evaluation. $\mathbf{J}$ Head Trauma Rehabil 23:230-242, 2008

17. Giordano C, Kleiven S: Evaluation of axonal strain as a predictor for mild traumatic brain injuries using finite element modeling. Stapp Car Crash J 58:29-61, 2014

18. Giza CC, Hovda DA: The neurometabolic cascade of concussion. J Athl Train 36:228-235, 2001

19. Gottshall KR, Hoffer ME: Tracking recovery of vestibular function in individuals with blast-induced head trauma using vestibular-visual-cognitive interaction tests. J Neurol Phys Ther 34:94-97, 2010

20. Gurdjian ES, Lissner HR, Webster JE, Latimer FR, Haddad BF: Studies on experimental concussion: relation of physiologic effect to time duration of intracranial pressure increase at impact. Neurology 4:674-681, 1954

21. Hardy WN, Foster CD, Mason MJ, Yang KH, King AI, Tashman S: Investigation of head injury mechanisms using neutral density technology and high-speed biplanar X-ray. Stapp Car Crash J 45:337-368, 2001

22. Holbourn AHS: Mechanics of head injuries. Lancet 242:468-441, 1943

23. Horgan TJ, Gilchrist MD: The creation of three-dimensional finite element models for simulating head impact biomechanics. Int J Crash 8:353-366, 2003

24. Horgan TJ, Gilchrist MD: Influence of FE model variability in predicting brain motion and intracranial pressure changes in head impact simulations. Int J Crash 9:401-418, 2004

25. Hoshizaki B, Post A, Kendall M, Karton C, Brien S: The relationship between head impact and brain trauma. J Neurol Neurophys 5:1, 2013

26. Júlíusson PB, Roelants M, Nordal E, Furevik L, Eide GE, Moster D, et al: Growth references for 0-19 year-old Norwegian children for length/height, weight, body mass index and head circumference. Ann Hum Biol 40:220-227, 2013

27. Kendall M, Walsh ES, Hoshizaki TB: Comparison between Hybrid III and Hodgson-WSU headforms by linear and an- gular dynamic impact response. J Sport Eng Tech 226:260 265, 2012

28. King AI, Yang KH, Zhang L, Hardy W, Viano DC: Is head injury caused by linear or angular acceleration? in $\mathbf{2 0 0 3}$ IRCOBI Conference Proceedings. Zurich: IRCOBI, 2003, pp 1-12 (http://www.ircobi.org/wordpress/downloads/ irc0111/2003/BertilAldmanLecture/0.1.pdf) [Accessed January 5, 2017]

29. Kleiven S: Predictors for traumatic brain injuries evaluated through accident reconstructions. Stapp Car Crash J 51:81114, 2007

30. Kleiven S, von Holst H: Consequences of head size following trauma to the human head. J Biomech 35:153-160, 2002

31. McCrory P, Meeuwisse WH, Aubry M, Cantu B, Dvorák J, Echemendia RJ, et al: Consensus statement on concussion in sport: the 4th International Conference on Concussion in Sport held in Zurich, November 2012. Br J Sports Med 47:250-258, 2013

32. Meaney DF, Smith DH: Biomechanics of concussion. Clin Sports Med 30:19-31, vii, 2011

33. Mendis KK, Stalnaker RL, Advani SH: A constitutive relationship for large deformation finite element modeling of brain tissue. J Biomech Eng 117:279-285, 1995

34. Mennes M, Jenkinson M, Valabregue R, Buitelaar JK, Beckmann C, Smith S: Optimizing full-brain coverage in human brain MRI through population distributions of brain size. Neuroimage 98:513-520, 2014

35. Miller K, Chinzei K: Constitutive modelling of brain tissue: experiment and theory. J Biomech 30:1115-1121, 1997

36. Miller R, Margulies SS, Leoni M, Nonaka M, Chen X, Smith $\mathrm{D}$, et al: Finite element modeling approaches for predicting injury in an experimental model of severe diffuse axonal injury. Stapp Car Crash J 42:155-166, 1998

37. Morgan CD, Zuckerman SL, Lee YM, King L, Beaird S, Sills AK, et al: Predictors of postconcussion syndrome after sports-related concussion in young athletes: a matched casecontrol study. J Neurosurg Pediatr 15:589-598, 2015

38. Morrison B III, Cater HL, Wang CCB, Thomas FC, Hung CT, Ateshian GA, et al: A tissue level tolerance criterion for living brain developed in an in vitro model of traumatic mechanical loading. Stapp Car Crash J 47:39-105, 2003

39. Nahum AM, Smith R, Ward C: Intracranial pressure dynamics during head impact. Stapp Car Crash J 21:339-366, 1977

40. National Centre for Injury Prevention: Report to Congress on Mild Traumatic Brain Injury in the United States: Steps to Prevent a Serious Public Health Problem. Atlanta: National Center for Injury Prevention, 2003

41. Nellhaus G: Head circumference from birth to eighteen years. J Am Academy Ped 41:106-114, 1968

42. Newman JA, Shewchenko N, Welbourne E: A proposed new biomechanical head injury assessment function-the maximum power index. Stapp Car Crash J 44:215-247, 2000

43. Nguyen AKD, Simard-Meilleur AA, Berthiaume C, Godbout $\mathrm{R}$, Mottron L: Head circumference in Canadian male adults: development of a normalized chart. Int J Morphol 30:14741480,2012

44. Ommaya AK, Goldsmith W, Thibault L: Biomechanics and neuropathology of adult and paediatric head injury. Br J Neurosurg 16:220-242, 2002

45. O'Riordain K, Thomas PM, Phillips JP, Gilchrist MD: Reconstruction of real world head injury accidents resulting from falls using multibody dynamics. Clin Biomech (Bristol, Avon) 18:590-600, 2003

46. Padgaonkar AJ, Kreiger KW, King AI: Measurement of angular acceleration of a rigid body using linear accelerometers. J Appl Mech 42:552-556, 1975

47. Patton DA, McIntosh AS, Kleiven S: The biomechanical determinants of concussion: finite element simulations to inves- 
tigate tissue-level predictors of injury during sporting impacts to the unprotected head. J Appl Biomech 31:264-268, 2015

48. Pellman EJ, Viano DC, Tucker AM, Casson IR, Waeckerle JF: Concussion in professional football: reconstruction of game impacts and injuries. Neurosurgery 53:799-814, 2003

49. Post A, Hoshizaki B, Gilchrist MD: Finite element analysis of the effect of loading curve shape on brain injury predictors. J Biomech 45:679-683, 2012

50. Post A, Hoshizaki TB: Rotational acceleration, brain tissue strain, and the relationship to concussion. J Biomech Eng 137:030801, 2015

51. Post A, Hoshizaki TB, Gilchrist MD, Brien S, Cusimano MD, Marshall S: The influence of dynamic response and brain deformation metrics on the occurrence of subdural hematoma in different regions of the brain. J Neurosurg 120:453-461, 2014

52. Post A, Kendall M, Koncan D, Cournoyer J, Hoshizaki TB, Gilchrist MD, et al: Characterization of persistent concussive syndrome using injury reconstruction and finite element modelling. J Mech Behav Biomed Mater 41:325-335, 2015

53. Roth S, Vappou J, Raul JS, Willinger R: Child head injury criteria investigation through numerical simulation of real world trauma. Comput Methods Programs Biomed 93:3245, 2009

54. Rousseau P: An Analysis of Dynamic Concussion Metrics Associated with Elite Ice Hockey Elbow-to-Head and Shoulder-to-Head Collisions [thesis]. Ottawa: University of Ottawa, 2014

55. Ruan JS: Impact Biomechanics of Head Injury by Mathematical Modeling [thesis]. Detroit: Wayne State University, 1994

56. Ruan SJ, Li PD, Li HY, Zhao W: Development and validation of a 6-year-old child finite element head model. Chinese J Biomed Eng 31:502-506, 2012

57. Sady MD, Vaughan CG, Gioia GA: Psychometric characteristics of the postconcussion symptom inventory in children and adolescents. Arch Clin Neuropsychol 29:348-363, 2014

58. Seifert TD, Evans RW: Posttraumatic headache: a review. Curr Pain Headache Rep 14:292-298, 2010

59. Selassie AW, Wilson DA, Pickelsimer EE, Voronca DC, Williams NR, Edwards JC: Incidence of sport-related traumatic brain injury and risk factors of severity: a population-based epidemiologic study. Ann Epidemiol 23:750-756, 2013

60. Sullivan S, Coats B, Margulies SS: Biofidelic neck influences head kinematics of parietal and occipital impacts following short falls in infants. Accid Anal Prev 82:143-153, 2015

61. Thomas LM, Roberts VL, Gurdjian ES: Experimental intracranial pressure gradients in the human skull. J Neurol Neurosurg Psychiatry 29:404-411, 1966

62. Uchiyama HT, Seki A, Tanaka D, Koeda T: A study of the standard brain in Japanese children: morphological comparison with the MNI template. Brain Dev 35:228-235, 2013

63. Weeks D, Sullivan S, Kilbaugh T, Smith C, Margulies SS: Influences of developmental age on the resolution of diffuse traumatic intracranial hemorrhage and axonal injury. J Neurotrauma 31:206-214, 2014

64. Willinger R, Taled L, Pradoura P: Head biomechanics from finite element model to the physical model. Proc IRCOBI 23:245-259, 1995

65. Wong RH, Wong AK, Bailes JE: Frequency, magnitude, and distribution of head impacts in Pop Warner football: the cumulative burden. Clin Neurol Neurosurg 118:1-4, 2014

66. Wright RM, Post A, Hoshizaki B, Ramesh KT: A multiscale computational approach to estimating axonal damage under inertial loading of the head. J Neurotrauma 30:102-118, 2013

67. Yeates KO, Kaizar E, Rusin J, Bangert B, Dietrich A, Nuss $\mathrm{K}$, et al: Reliable change in postconcussive symptoms and its functional consequences among children with mild traumatic brain injury. Arch Pediatr Adolesc Med 166:615-622, 2012

68. Yoganandan N, Li J, Zhang J, Pintar FA, Gennarelli TA: Influence of angular acceleration-deceleration pulse shapes on regional brain strains. J Biomech 41:2253-2262, 2008

69. Yue JK, Winkler EA, Burke JF, Chan AK, Dhall SS, Berger MS, et al: Pediatric sports-related traumatic brain injury in United States trauma centers. Neurosurg Focus 40(4):E3, 2016

70. Zemek R, Barrowman N, Freedman SB, Gravel J, Gagnon I, McGahern C, et al: Clinical risk score for persistent postconcussion symptoms among children with acute concussion in the ED. JAMA 315:1014-1025, 2016

71. Zhang L, Yang KH, King AI: Comparison of brain responses between frontal and lateral impacts by finite element modeling. J Neurotrauma 18:21-30, 2001

72. Zhang L, Yang KH, King AI: A proposed injury threshold for mild traumatic brain injury. J Biomech Eng 126:226236, 2004

73. Zhou C, Khalil TB, King AI: A new model for comparing responses of the homogeneous and inhomogeneous human brain. Stapp Car Crash J 39:121-136, 1995

74. Zong XN, Li H: Construction of a new growth references for China based on urban Chinese children: comparison with the WHO growth standards. PLoS One 8:e59569, 2013

\section{Disclosures}

The authors report no conflict of interest concerning the materials or methods used in this study or the findings specified in this paper.

\section{Author Contributions}

Conception and design: Post, Hoshizaki, Zemek. Acquisition of data: Post, Koncan, Dawson, Chen. Analysis and interpretation of data: Post, Hoshizaki, Zemek, Koncan, Dawson, Chen. Drafting the article: Post, Hoshizaki, Zemek, Koncan. Critically revising the article: all authors. Reviewed submitted version of manuscript: all authors. Approved the final version of the manuscript on behalf of all authors: Post. Statistical analysis: Post. Study supervision: Post, Hoshizaki, Zemek, Gilchrist.

\section{Correspondence}

Andrew Post, 200 Lees Ave., Rm. A106, Ottawa, ON K1N 6N5, Canada.email: apost@uottawa.ca. 